IRA-International Journal of Education \& Multidisciplinary Studies

ISSN 2455-2526; Vol.04, Issue 03 (2016)

Pg. no. 387-396

Institute of Research Advances

http://research-advances.org/index.php/IJEMS

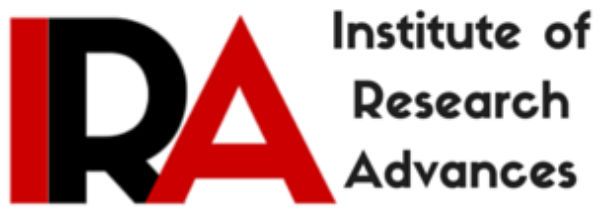

\title{
Learning Strategies Used by Urban and Rural School Students in Mathematics
}

Bishnu Khanal, (Ph.D.)

Tribhuvan University, Mahendra Ratna Campus,

Tahachal, Kathmandu, Nepal.

Type of Review: Peer Reviewed.

DOI: http://dx.doi.org/10.21013/jems.v4.n3.p5

\section{How to cite this paper:}

Khanal, B. (2016). Learning Strategies Used by Urban and Rural School Students in Mathematics. IRA International Journal of Education and Multidisciplinary Studies (ISSN 2455-2526), 4(3), 387-396. doi:http://dx.doi.org/10.21013/jems.v4.n3.p5

(C) Institute of Research Advances

(cc) EY-NC

This work is licensed under a Creative Commons Attribution-Non Commercial 4.0 International License subject to proper citation to the publication source of the work.

Disclaimer: The scholarly papers as reviewed and published by the Institute of Research Advances (IRA) are the views and opinions of their respective authors and are not the views or opinions of the IRA. The IRA disclaims of any harm or loss caused due to the published content to any party. 


\begin{abstract}
The paper attempts to find out the difference in preferred learning strategies in mathematics between urban and rural school students in Nepal. The study was conducted in 1394 grade IX students through multistage sampling procedure throughout the country. Among them, 987 students were from urban schools, and 407 students were from rural schools. The researcher adopted mix method-sequential explanatory design. The study was based on taxonomy of learning strategies developed by Pintrich, Smith and McKeachie (1989). The tools for the data collection were Motivated Strategies for Learning Questionnaire (MSLQ), observation and interview. The study shows that there is significant difference in preferred learning strategies of urban and rural school students. There was a significant difference in the use of mathematics learning strategies between urban and rural school students. Elaboration and organization strategies were more often used by rural students than urban school students whereas peer learning, elaboration, help seeking and effort management strategies were more often used by urban school students. However, students from both of the locations mostly used peer learning and elaboration learning strategies.
\end{abstract}

Keywords: Learning strategies, urban school students, rural school students

\title{
BACKGROUND OF THE STUDY
}

Nepal is geographically a diverse country. It has three different geographical reasons-Mountain, Hilly and Terai. The infrastructures of development and resources are not equally distributed all over the country. Mostly, people having less income are the habitants of rural places. Economically sound and elite people are living in urban area. Due to lack of resources and rural setting, the rural school students have no enough access to education as compared to urban school students. The average pass rate of rural school students is lesser than urban areas. As indicated by the report presented by Mathema and Bista (2006), there is regional difference in the academic performance of students. Mathematics is a compulsory subject up to secondary level (Grade IX and X) in school education. Though the school curriculum in Nepal aims to provide quality of education and the teachers have been trained, it has been challenging for mathematics teachers because of low scores of students, large number of students in the classroom and public concept of taking mathematics as a difficult subject. The average mark in mathematics is less than the average marks in other subjects. Average achievement of grade VIII students in Mathematics is 28.87 lower than Science (29.62), English (34.29) and Nepali (68.80) (CERID, 1999).

The National Assessment of Student Achievement taken in 2011 (result published in 2013) of grade VIII students stated that though the results were somehow better in cities than in the rural area, the difference was not remarkably high. From equity viewpoint, this was a positive thing (Acharya, Metsämuuronen, \& Koirala, 2013). In the same kind of research, National Assessment of Student Achievement 2012 of grade V students reported a remarkable rise in performance within the urban schools in the last 14 years (Acharya \& Metsämuuronen, 2014). This report section compared the achievement of the rural students and urban students in the year 1999 and 2012. Based on those reports, it could be assumed that there was significant difference in learning strategy between the rural students and urban students. 
Learning strategies are an individual's approach to a task. They are how a student organizes and uses a set of skills to learn content to accomplish a particular task more effectively and efficiently either in or out of school (Schumaker \& Deshler, 1984). Learning strategies are particular actions employed by learners to make their learning easier, faster, more enjoyable, more directed, more effective and more transferable to new situations. The learning strategies, as taxonomy developed by Pintrich, Smith and Mckeachie (1989), consist of cognitive strategies (rehearsal, elaboration, organization, critical thinking and metacognition) and resource management strategies (time and study management, effort management, peer learning and help seeking). According to them, rehearsal refers to students' use of strategies to recall and repeat learning material and elaboration includes summarizing information and putting ideas into one's own words. Organization concerns students' use of strategies to make connections across learning experiences while critical thinking denotes how learners question or analyze statements and concepts learned in the class. Similarly, metacognition concerns how students set learning goals and monitor/regulate the learning process. Likewise, time and study management refers to the strategies adopted by students to manage their time and learning environment. Effort management concerns to the students' commitment to achieve their learning goals even when there are difficulties. Peer learning includes the strategies adopted by students to work with their friends and classmates and help-seeking involves how students seek assistance from their teachers and classmates in the learning process.

As research suggests, effective use of learning strategies can greatly improve student achievement (Protheroe \& Clarke, 2008). In order to improve the academic performance of all students, teachers need to help students develop effective learning strategies that enable them to construct their own mathematical knowledge, discover relationships and find facts by using their own learning styles and strategies rather than memorizing mathematical formulas and procedures (Cangelosi, 1996). Cangelosi further states mathematics learning strategies are specific techniques used to promote and enhance mathematics learning.

Even though many researchers and theorists (O'Malley and et al., 1985; Pintrich, Smith and Mckeachie, 1989; Oxford, 1990; Mayer, 1992; Cangelosi, 1996; Oxford and Green, 1996 and Wolters, 1999) have tried to define and classify learning strategies, they have not provided any suggestion regarding what learning strategies do students of different location use in mathematics? The study about learning strategies used by urban and rural school students in mathematics has not been carried out in the Nepalese context. The culture, context and cognition of Nepalese students are different. Hence; the research aims to investigate the learning strategies used by urban and rural school students in the learning of mathematics in Nepalese context. 


\section{RESEARCH QUESTION}

This study tries to answer the following question related to the learning strategies of secondary school mathematics students:

1. Is there any difference between urban and rural school students in their preferred learning strategies in mathematics?

2. What kinds of differences between urban and rural school students are there in their preferred learning strategies in mathematics?

\section{METHOD}

This study was based on the learning strategies classified by Pintrich, Smith and Mckeachie (1989) to answer the research questions. The researcher has employed mix method-sequential explanatory design (Creswell, 2014). Information, from 1394 students of Grade IX from 24 (16 urban and 8 rural) schools of three geographical regions of Nepal selected through multi-stage sampling, was collected from survey, interview and observation method. In this study, the school which are in district headquarter or municipality were considered as urban school and the schools which are in periphery in rural setting were taken as rural school. Quantitative information was collected by adapting Motivated Strategies for Learning Questionnaire (MSLQ) developed by Pintrich, Smith and Mckeachie (1989). The data were analyzed by applying $\chi^{2}-$ test through SPSS. To authenticate the finding derived, 12 students were selected purposively from both types of schools in one of the geographical regions as the sample for qualitative study.

\section{RESULTS AND DISCUSSION}

The null hypothesis assumed by the research question was: Both urban school students and rural school students used all nine learning strategies in equal proportion. The chi-square test for goodness of fit was carried out to test the null hypothesis. Students of different location might have different physical facilities and methods of teaching. Consequently the learning strategies could also be different because of those resources, teaching methods and environment. Percentage of students who selected different learning strategies based on location (rural and urban) is plotted in the following figure taking the idea that if the school was in district headquarter or municipality it was named - Urban and if not - Rural. 


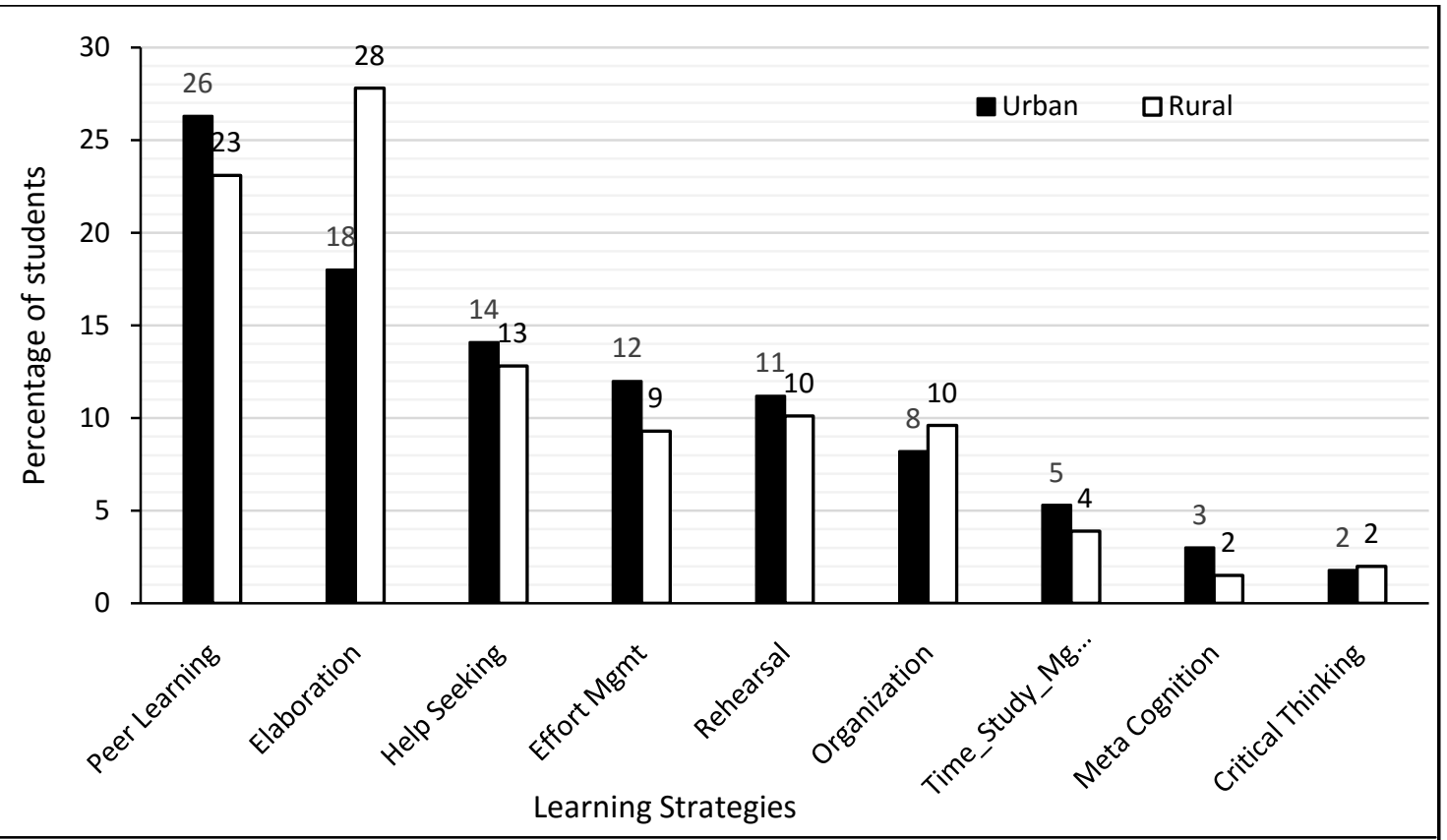

Figure 1. Learning Strategies Percentage of Students in Urban and Rural Locations

From figure 1, it is clear that most of the urban students used peer learning whereas rural students used elaboration. Second highest learning strategy of urban students was elaboration whereas that of rural students was peer learning. However, students from both of the locations mostly used peer learning and elaboration.

To identify whether there was difference, chi-square test was carried out. During the process, a table of observed count and expected count is given in table 1.

Table 1

Observed and Expected Counts of Urban and Rural School Students

District Headquarter/Municipality (Yes - 1, No - 2) Cross tabulation

\begin{tabular}{lllll}
\hline Selected Strategy & & \multicolumn{2}{l}{ District Headquarter/Municipality } & Total \\
\cline { 3 - 5 } & & Yes & No & 152 \\
Rehearsal & Observed Count & 111 & 41 & 152 \\
\multirow{2}{*}{ Elaboration } & Expected Count & 107.6 & 44.4 & 291 \\
& Observed Count & 178 & 113 & 291 \\
Organization & Expected Count & 206 & 85 & 120 \\
\multirow{2}{*}{ CriticalThinking } & Observed Count & 81 & 39 & 120 \\
\multirow{2}{*}{ MetaCognition } & Expected Count & 85 & 35 & 26 \\
& Observed Count & 18 & 8 & 26 \\
Time_Study_Mgmt & Expected Count & 18.4 & 7.6 & 36 \\
\multirow{2}{*}{ Effort_Mgmt } & Experved Count & 30 & 6 & 36 \\
& Observed Count & 52 & 16 & 68 \\
\hline
\end{tabular}




\begin{tabular}{lllll}
\hline & Expected Count & 110.5 & 45.5 & 156 \\
Peer_Learning & Observed Count & 260 & 94 & 354 \\
& Expected Count & 250.6 & 103.4 & 354 \\
Help_Seeking & Observed Count & 139 & 52 & 191 \\
& Expected Count & 135.2 & 55.8 & 191 \\
Total & Observed Count & 987 & 407 & 1394 \\
& Expected Count & 987 & 407 & 1394 \\
\hline
\end{tabular}

Table 2.

Chi-Square Tests

\begin{tabular}{llll}
\hline & Value & df & Asymp. Sig. (2-sided) \\
\cline { 2 - 4 } Pearson Chi-Square & 21.208 a & 8 & 0.007 \\
No. of Valid Cases & 1394 & & \\
\hline
\end{tabular}

Table 2 shows that learning strategy between the rural students and urban students differ significantly at $\mathrm{p}<0.001$ and concluded that urban and rural school students used different learning strategies. Learning strategies of high school students varied among individual students and groups of students. However, all kinds of strategies were used by some percentage of students

Indeed, individuality in learning existed in today's classrooms. However, patterns of repetitive and consistent learning behavior in the classroom were also observed. For example, certain students became actively involved in verbalizing thoughts, while others preferred hands-on experiences. Remaining students passively absorbed their environment. Such patterned behaviors were characteristic of basic strategies of learning.

The researcher's observation and experiences showed that many children in rural setting lived in poverty and their opportunities for learning and life experiences were limited. Rural schools needed to rely on technology to provide students with additional learning opportunities and teachers with necessary professional development. Technology could enable students to access a wider range of curricular contents than was available at the school. Rural schools were often limited in the range of classes they could offer, in access to educational resources that might enhance students' learning in their particular areas of interest, and in the ability to provide remedial support to struggling students (Redding \& Walberg, 2012). Researcher's introspection even showed that lack of technology had disabled innovations and provided enriched classroom instructions to students in rural schools. Similarly, rural communities tended to rely strong on farming, and students needed to learn the most current skills and practices to be competitive. But they had difficulties to make themselves up-to-date. Moreover, rural schools had difficulty recruiting and retaining new teachers because of location. The teachers teaching in rural schools also lacked technological skills, and they had not kept themselves up-to-date. Likewise, some families in rural communities did not see the value of education. So the students were forced to engage in activities other than concentration on their study. They could not concentrate only on their study, which had caused problems in their learning strategies and achievement. On the other hand, the schools in urban setting had a greater and easier access to technologies which kept themselves up-to-date in the skills and experiences. Students had easy access to education, and 
access to wider range of reference materials. They could concentrate on their study. Their attitudes and beliefs had a strong impact on their performance in a particular subject area. The parents of urban setting also had positive attitude towards education. These factors played important roles in developing learning strategies.

In the observation, it was found that the rate of absence of teachers and students was higher in rural schools than in urban schools. In rural setting, mathematics teachers used teaching materials less than the teachers in the urban setting schools. The classrooms were quieter in urban schools than in rural schools. Teachers encouraged cooperative learning. Therefore, the students of urban schools were more likely to use peer learning as the major strategy to learn mathematics. The researcher observed significant differences in the classroom environments between the urban and rural schools. The urban classrooms were set to be somehow more conducive to learning than the classrooms in rural schools. The teachers in the urban schools seemed to be faced with maintaining on-task behavior situation during class time. These factors had contributed to the students for being more attentive in their study.

The design of mathematics curriculum also had played influencing role for the development of learning strategies and achievement in mathematics. The present curriculum of mathematics was elite favoured and feasible for understanding to the students of urban areas who could get sufficient family support and school provided learning opportunities (Sharma, 2007). This curriculum was not the discourse of the rural students, but thought out on the basis of learning opportunities available in urban elite culture, which was not suitable for the poor rural students. As the course itself was designed to meet the need of urban students, they were more likely to develop more positive attitude towards mathematics whereas the poor rural students developed distrust for mathematics. As a result, urban students used more learning strategies; however, the rural students depended on limited learning strategies. Though some rural students were seen using all nine learning strategies, they used elaboration, peer learning and help seeking mostly in respective order, whereas the urban students used peer learning, elaboration, help seeking and effort management highly in respective order. Thus, significant variations were noted between students in urban and rural schools in learning mathematics.

Concerning the mathematics learning strategies, urban students preferred peer learning than other strategies. "I copy the homework from friends if I can't do myself. I learn from them too", said one of the urban school students in interview. In the observation also, urban students were seen solving problems asking with friends. They used to copy homework and class works also. They were more willing to seek help too. They were likely to ask questions with their teachers, family members and relatives. An interviewee admitted openly, "If I don't understand, at first, I ask my friends. If I'm still confused, I ask my teacher. At home my sister teaches me to solve difficult problems." Similarly, they were more likely to use effort management also. They sometimes tried to solve the problems by themselves also. "I generally go through the lessons before the teacher teaches. Sometimes I try to solve using different method also", claimed a student from an urban school. Elaboration was also another noted strategy the urban school students used in learning mathematics. The researcher saw students keeping notes while teachers solved problems on board. They even reported making lists and charts. They were also seen summarizing the mathematics concepts and ideas which they had studied in previous classes. "I look at the board while teacher solves the problems, try to understand it; and solve similar problems myself 
following the method the teacher has used," one of the high achieving urban school students replied in interview. She even said, "Sometimes I relate the ideas I had studied in class VII and VIII to solve some problems, and solve before our teacher teaches us." To sum up, the urban school students were likely to use peer learning, elaboration, help seeking and effort management respectively. Fewer students were likely to use other strategies.

In contrast, the mathematics learning strategies used by rural students, they were more likely to use elaboration. They mostly depended on the elaboration strategy to learn mathematics. They mostly depended on books and notes for their learning resource. They made the note when the teacher taught and solved problems looking upon the notes. One of the respondents of rural school said, "I solve problems before exams looking the notes which I made during our sir had taught us." Another respondent admitted, "I get help from the examples worked out in the books while solving problems." Rural school students also used peer learning to some extent, however, the urban school students were more likely to use this strategy. One of the girls from rural school said, "I ask my friends, especially girls, when I don't understand any problem." While comparing, the rural school students preferred elaboration whereas the urban school students preferred peer learning. While comparing all nine strategies, urban school students excelled to use almost all the strategies except for elaboration and organization in which rural students excelled.

There was a significant difference in the use of mathematics learning strategies between urban school students and rural school students. The urban school students preferred peer learning whereas the rural school students preferred elaboration as their effective learning strategy. While comparing all nine strategies, urban school students excelled in almost all the strategies except for elaboration and organization in which rural schools students excelled. The urban school students had the reach to many resources for study; however, rural school students did not have such facilities. They depended mostly on books and notes which they used to solve problems. This finding is supported by Redding and Walberg (2012) when they claim that rural schools are often limited in the range of classes they offer, in access to educational resources that might advance students' learning in their particular areas of interest, and in the ability to provide remedial support to struggling students. As the rural school students lived in poverty and they lacked many resources for study, they needed to rely on the limited resources; they had no alternatives.

Similarly, parents' attitude, cultural background, and learning environment also played important roles to develop learning strategies. Rural school students' parents were mostly uneducated who had negative attitude towards education; they did not encourage students to concentrate on the study, whereas the urban school students' parents had positive attitude towards education. They were constantly encouraged by their parents to study. This helped them to develop learning strategies and use them for their benefit. Therefore, the urban school students themselves developed more concern about their study. This claim is consistent with the claim of Peterson (1978) who claims that adolescents from large urban communities thought more highly about themselves than did adolescents from rural communities. After students become self aware, they are likely to develop individual strategies to assist themselves to achieve their mathematical aspirations. Cox, Sproles \& Sproles (1988) found significant differences between rural and urban school students as he reports variations in preferred learning styles between students in rural and 
urban school settings. Likewise, the "elite favoured" (Sharma, 2007) curriculum has also contributed negatively for the rural students to use multiple learning strategies. This curriculum is not the discourse of rural students, but thought out on the basis of learning opportunities available in the urban elite culture, which is not suitable for poor rural students. This has also discouraged rural students to develop varied learning strategies. As a result, the achievement level of rural students in Nepal is comparatively far below urban students. This has contributed to create dislike for mathematics in most of the rural students. They become passive in mathematics class. They think mathematics is not the subject for them. This negative attitude prevents them from being creative versatile reader. These adverse situations in rural setting schools have confined rural students to use limited learning strategies. Elaboration and organizational strategies are mostly used by rural students, though some of them used all nine strategies to some extent. But urban school students used peer learning, elaboration, help seeking and effort management remarkably more often than rural students.

\section{CONCLUSION}

There is a significant difference between urban and rural school students in their use of learning strategies. The urban school students prefer peer learning whereas rural school students use elaboration as their effective learning strategies. While comparing all the nine strategies discussed in this study, urban school students are far ahead in almost all the strategies except for elaboration and organization. Rural school students' family background, attitude, environment, cultural value system, limited exposure to the learning resources and materials are the major causes for these differences. The design of mathematics curriculum, which is elite favoured, is also another cause for this difference. However, the urban school students have a greater reach in the technology and educational resources. The rural school students' uneducated family background has disabled them to form efficient learning strategies and affected their achievement level. Unlikely, the urban school students have easy access to educational resources, technology, and educated family background which have enabled them to develop and use effective learning strategies, and achieve high. These adverse situations have discouraged the rural school students to develop and use effective learning strategies, therefore, they use limited learning strategies. Elaboration and organization strategies are more often used by rural students than urban school students whereas peer learning, elaboration, help seeking and effort management strategies are more often used by urban school students. However, students from both of the locations mostly use peer learning and elaboration learning strategies. Acknowledging the finding of this study, the researcher suggests to adjust the different setting of the students' learning environment in teaching and learning in mathematics education.

\section{References}

Acharya, S. P. \& Metsämuuronen, J. (2014). Mathematics achievement at Grade 5 in NASA 2012. Kathmandu: Ministry of Education, Education Review Office.

Acharya, S. P., Metsämuuronen, J., \& Koirala, S. (2013). National Assessment of Student Achievement 2011. In J. M. (Eds), Where Are We Now? (p. 468). Kathmandu: Education Review Office.

Cangelosi, J. S. (1996). Teaching mathematics in secondary and middle school: An interactive approach (2nd ed.). NJ: Prentice Hall, Inc. 
Cox, D. E., Sproles, E. K. \& Sproles, G. B. (1988). Learning style variations between rural and urban students. Research in Rural Education, 5(1), 27.

Creswell, J. W. (2014). Research design: Qualitative, quantitative, and mixed methods. approaches. New Delhi: SAGE Publications India Pvt. Ltd.

Mathema, K. B. \& Bista, M. B (2006). Study on student performance in SLC: Main report. Kathmandu: Government of Nepal, Ministry of Education and Sports, Education Sector Advisory Team.

Mayer, R. E. (1992). Cognition and instruction: Their historic meeting within educational psychology. Journal of Educational Psychology, 84, 405-412.

O'Malley \& et .al. (1985). Learning strategies application with students of English as a secondary language. TESOL Quarterly 19, 557-584.

Oxford. (1990). Language learning strategies: What every teacher should know. New York: Newbury House/ Harper and Row.

Oxford, R. \& Green, J. M. (1996). Language learning histories: Learners and teachers helping each other understand learning styles and strategies. TESOL Journal, 6(1), 20-23.

Peterson, A. C. (1978). The self-image of rural adolescent girls. ERIC Document Reproduction Service Document No. ED 168179.

Pintrich, P. R., Smith, D. A. F., \& Mckeachie, W. J. (1989). A Manual for the use of the

Motivated Strategies for Learning Questionnaire (MSLQ). Mich: National center for Research to improve Postsecondary Teaching and Learning (NCRIPTAL), School of Education, The University of Michigan.

Protheroe, N. \& Clarke, S. (2008). Learning strategies as a key to student success. Principal, $88(2), 33-37$.

Redding, S. and Walberg, H. J. (2012). Promoting learning in rural schools. Lincoln, IL: Center on Innovation and Improvement. Retrieved from http://www.centerii.org/survey/downloads/Promoting_Learning_inRural_Schools.pdf.

Research Center for Educational Innovation and Development (CERID) (1999). Assessment of learning achievement of lower-secondary children. Kathmandu: SEDP/MOES.

Schumaker, J. B., \& Deshler, D. D. (1984). Setting demand variables: A major factor in program planning for LD adolescents. Topics in language disorders, 4, 22-44.

Sharma, L. (2007). A study of curriculum standards: Implications of the desired and existing standards for the reform of mathematics education in Nepal. Doctoral dissertation, Faculty of Education, T. U.

Wolters, C. A. (1999). The relation between high school students motivational regulation and their use of learning strategies, effort, and classroom performance. Learning and individual differences: Maintaining the motivation to learn, 11(3), 281-299. 